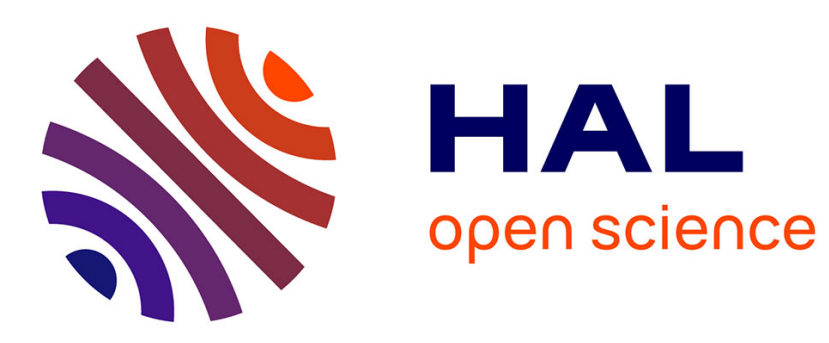

\title{
On the time-dependent behaviour of unsaturated geomaterials
}

Jean-Michel Pereira, Vincenzo de Gennaro

\section{To cite this version:}

Jean-Michel Pereira, Vincenzo de Gennaro. On the time-dependent behaviour of unsaturated geomaterials. Unsaturated Soils - Proc. Fifth Int. Conf. on Unsaturated Soils, Sep 2010, Barcelona, Spain. pp.921-925. hal-00525903

\section{HAL Id: hal-00525903 \\ https://hal.science/hal-00525903}

Submitted on 13 Oct 2010

HAL is a multi-disciplinary open access archive for the deposit and dissemination of scientific research documents, whether they are published or not. The documents may come from teaching and research institutions in France or abroad, or from public or private research centers.
L'archive ouverte pluridisciplinaire HAL, est destinée au dépôt et à la diffusion de documents scientifiques de niveau recherche, publiés ou non, émanant des établissements d'enseignement et de recherche français ou étrangers, des laboratoires publics ou privés. 


\title{
On the time-dependent behaviour of unsaturated geomaterials
}

\author{
J.M. Pereira \& V. De Gennaro* \\ Université Paris-Est, UR Navier, École des Ponts ParisTech, Marne-la-Vallée, France. \\ *presently at Schlumberger, EPRC-DCS, Pau, France.
}

\begin{abstract}
In this paper a rate dependent model for unsaturated geomaterials is presented. The constitutive laws for the description of the time-dependent behaviour of saturated and partially saturated geomaterials generalize the isotach approach to the elastoplastic strain hardening based constitutive laws for partially saturated soils. The formulation encompasses rate and creep effects together with suction dependency on creep. It constitutes an extension of the work presented in (De Gennaro et al. 2009; Pereira and De Gennaro 2009). Some perspectives about the constitutive modelling of time-dependent behaviour of geomaterials saturated by a single or two fluids, including soft rocks are proposed. Practical applications include modelling of (i) shallow quarries submitted to humidity changes, (ii) oil reservoir formations or (iii) geological storage of $\mathrm{CO}_{2}$. In this study, the formulation of the constitutive model is presented. Numerical predictions including explicit influence of suction on time dependency of material's behaviour are compared to available experimental data on oil reservoir and quarry chalks and discussed.
\end{abstract}

\section{INTRODUCTION}

Mechanical behaviour of geomaterials usually exhibit a time dependency. This dependency may be distinguished on the basis of the deformational processes which are involved. It is generally observed a small dependency on applied strain rate of the material stiffness at small strains thus leading to mainly non-viscous elastic strains (see e.g. Sorensen et al. 2007 and Tatsuoka 2009). Regarding material strength, a significant dependence on the rate of applied load or strain may be experimentally observed. Irreversible deformation due to creep under constant applied load are also generally observed. Experimental creep curves classically show a proportionality of the strains to the logarithm of time, the proportionality coefficient being the secondary compression index $C_{\alpha}$ or $\lambda_{t}$, often used in engineering practice.

These experimental observations concern a large variety of materials, including sands, clays (Bjerrum 1967), rockfill (Oldecop and Alonso 2007), rocks and soft rocks (Šuklje 1957; Pasachalk 2004; Priol et al. 2007). Most of the preceding studies on this topic are related to saturated materials. Actually, despite a significant practical interest, only few studies have focused on the couplings between partial saturation states and time effects on the behaviour of geomaterials. Recently, researches on partially saturated rockfill material (Oldecop and Alonso 2007) and reser- voir chalk (Pasachalk 2004; Priol et al. 2007) have been published. These works clearly show the effects of partial saturation states on the time dependent behaviour (particularly on creep phenomena) of geomaterials.

In this paper, a brief overview of the observed influence of partial saturation or fluid nature on the time dependency of the mechanical behaviour is depicted. An elasto-visco-plastic constitutive model is then proposed and validated on the basis of experimental data on two different chalks (from oil reservoir and a shallow quarry).

\section{MODEL FORMULATION}

\subsection{Assumptions}

It is generally accepted that the elastic limit is related to the strain rate at which the material is loaded (e.g. Leroueil and Marques 1996):

$$
\sigma_{y}=A+\alpha \log \dot{\varepsilon}
$$

where $A$ and $\alpha$ are material parameters. As suggested by Figure 1 in the case of a reservoir chalk, parameters $A$ and $\alpha$ depend on the nature of the fluid (in particular its wettability) saturating the porous space and on the suction if the material is saturated by two immiscible fluids.

In the remaining part of the paper, it will be assumed that Eq. (1) is valid in the range of strain rates 




Figure 1: Evolution of yield stress of a reservoir chalk during constant rate of strain oedometric tests, $0.2 \mathrm{MPa}$ refers to oil-water suction (after Priol et al. 2007).

of practical interest in engineering (typically comprised between $10^{-8}$ to $10^{-4} \mathrm{~s}^{-1}$ ) and that the two parameters $A$ and $\alpha$ are suction-dependent. Relation (1) together with this latter assumption constitute the key point of the time-dependent constitutive modelling of unsaturated geomaterials proposed here. It is worth noting that the elastic regime of the mechanical behaviour will be assumed to be inviscid as mentioned in the introductory part of this paper.

\subsection{Constitutive model formulation}

The elastoplastic model presented here, called RASTRA, is a rate dependent model developed adopting the isotach approach proposed by Šuklje (1957) and Bjerrum (1967) within the framework of hardening plasticity. It is an extension of the works presented in (De Gennaro et al. 2009; Pereira and De Gennaro 2009). Besides the time dependent modelling, it also includes effects of partial saturation both on the time dependency itself and on the mechanical behaviour. These features have been developed on the basis of the well-known Cam-clay model for saturated soils and particularly its extension to unsaturated states proposed by Alonso et al. (1990): the Barcelona Basic Model (BBM). For the sake of conciseness, BBM will not be presented in detail here. As in (Alonso et al. 1990), net stress $\left(\overline{\boldsymbol{\sigma}}=\boldsymbol{\sigma}-u_{a}\right)$ and suction $\left(s=u_{a}-u_{w}\right)$ have been considered as stress state variables ( $\boldsymbol{\sigma}$ is the total stress tensor, $u_{a}$ and $u_{w}$ are the air and water pressures). It is worth noting that as far as stress state variables are concerned other choices are possible (see e.g. Pereira et al. 2005). Only triaxial stress states are considered in the following. The mean net stress $\bar{p}$ and deviatoric stress $q$ are thus classically introduced. Since it is assumed that time ef-

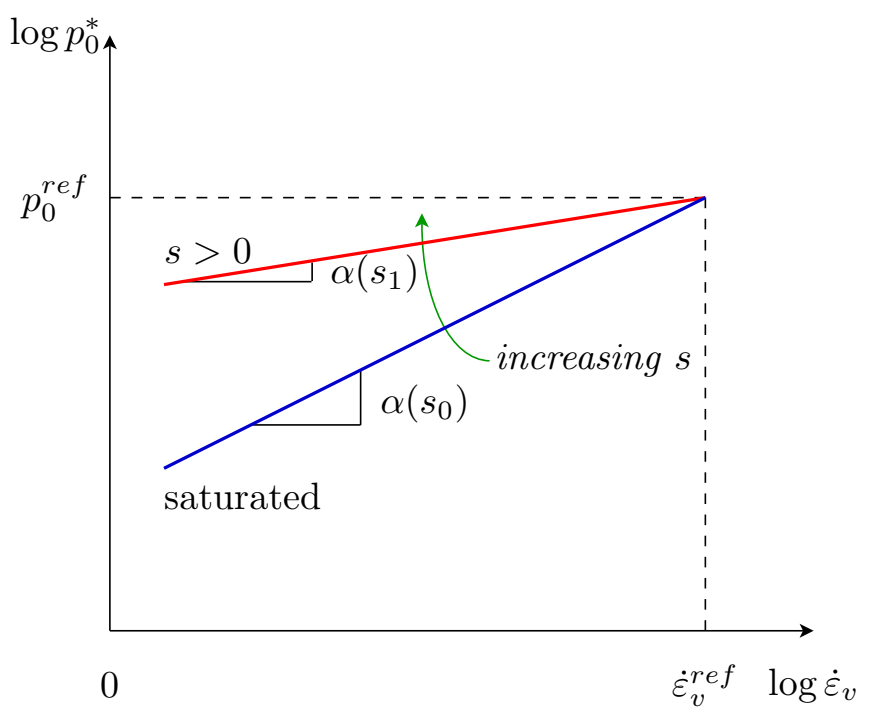

(a) Schematic representation of the evolution of the preconsolidation pressure with strain rate and coupled influence of suction.



(b) Evolution of the yield locus in $(\bar{p}, q)$ plane (under saturated conditions).

Figure 2: Influence of the applied volumetric strain rate on the yield locus.

fects do not influence the elastic behaviour of the material, the incremental elastic law of BBM is adopted without modification:

$$
\begin{aligned}
d \varepsilon_{v}^{e} & =\frac{\kappa}{1+e} \frac{d \bar{p}}{\bar{p}}+\frac{\kappa_{s}}{1+e} \frac{d s}{s+p_{a t m}} \\
d \varepsilon_{s}^{e} & =\frac{1}{3 G} d q
\end{aligned}
$$

where $\varepsilon_{v}^{e}$ and $\varepsilon_{q}^{e}$ are the elastic part of the volumetric and deviatoric strains respectively; $\kappa$ and $\kappa_{s}$ are the elastic stiffness parameters for changes in mean net stress and suction, respectively; $G$ is the shear modulus; $p_{a t m}$ is the atmospheric pressure taken as a reference datum and $e$ is the void ratio.

Concerning the plastic behaviour of unsaturated soils, the key feature of BBM is the introduction of an apparent suction hardening within the definition 
of the preconsolidation pressure, which defines the elastic limit under isotropic conditions, $p_{0}=p_{0}\left(\varepsilon_{v}^{p}, s\right)$. The proposition made in this paper extends this model to include rate effects by assuming that the preconsolidation stress also depends on the strain rate $\dot{\varepsilon}_{v}$, $p_{0}=p_{0}\left(\varepsilon_{v}^{p}, \dot{\varepsilon}_{v}, s\right)$. Considering expression (1), extension of BBM to include rate effects is introduced in the following way:

$$
p_{0}\left(\varepsilon_{v}^{p}, \dot{\varepsilon}_{v}, s\right)=p_{c}\left(\frac{p_{0}^{*}\left(\varepsilon_{v}^{p}, \dot{\varepsilon}_{v}\right)}{p_{c}}\right)^{\frac{\lambda(0)-\kappa}{\lambda(s)-\kappa}}
$$

where the saturated preconsolidation pressure reads:

$$
p_{0}^{*}\left(\varepsilon_{v}^{p}, \dot{\varepsilon}_{v}\right)=p_{0}^{r e f}\left(\frac{\dot{\varepsilon}_{v}}{\dot{\varepsilon}_{v}^{r e f}}\right)^{\alpha} \exp \left(\frac{1+e}{\lambda-\kappa} \varepsilon_{v}^{p}\right)
$$

As suggested by experimental observations reported in Fig. 1 and the schematic interpretation depicted in Figure 2(a), the parameter $\alpha$ is assumed to vary with suction. In a first approach, a simple linear relation is introduced:

$$
\alpha(s)=\alpha_{0}-b s
$$

Only three parameters related to the modelling of rate effects and their couplings with partial saturation have been introduced in the proposed model with respect to BBM, namely $\dot{\varepsilon}_{v}^{r e f}, \alpha_{0}$ and $b . p_{0}^{r e f}$ corresponds to the preconsolidation pressure of the undeformed material under saturated conditions if the material is loaded at the reference strain rate $\dot{\varepsilon}_{v}^{r e f}$. In practice, $p_{0}^{r e f}$ will be deduced from Eq. (5) if $p_{0}^{*}$ that is the saturated preconsolidation corresponding to a given strain rate at a reference (undeformed) state is given (see Figure 2).

The elastic domain is then delimited by defining the yield surface in triaxial stress space as follows:

$$
f\left(\boldsymbol{\sigma}, p_{0}\right) \equiv q^{2}-M^{2}\left(\bar{p}+p_{s}\right)\left(p_{0}-\bar{p}\right)=0
$$

where $p_{s}$ is the tensile strength for the material at a given suction $s$. As in the original $\mathrm{BBM}, p_{s}$ is assumed to depend linearly upon suction:

$$
p_{s}=k s
$$

where $k$ is a material parameter. It is worth noting that the yield locus associated to increases in suction (called SI in the original work by Alonso et al. (1990) is not introduced in this work.

The model is completed by giving the plastic flow rule. As in original BBM, it will be non-associated and chosen as $\left(\alpha_{g}\right.$ being a function of parameters $M$, $\lambda(0)$ and $\kappa$, see (Alonso et al. 1990) for more details):

$$
d \varepsilon_{v}^{p}=d \mu \frac{\partial f}{\partial \bar{p}} \quad ; \quad d \varepsilon_{q}^{p}=\alpha_{g} d \mu \frac{\partial f}{\partial q}
$$

where $d \mu>0$ is the plastic multiplier which can be obtained using the consistency condition $d f=0$.

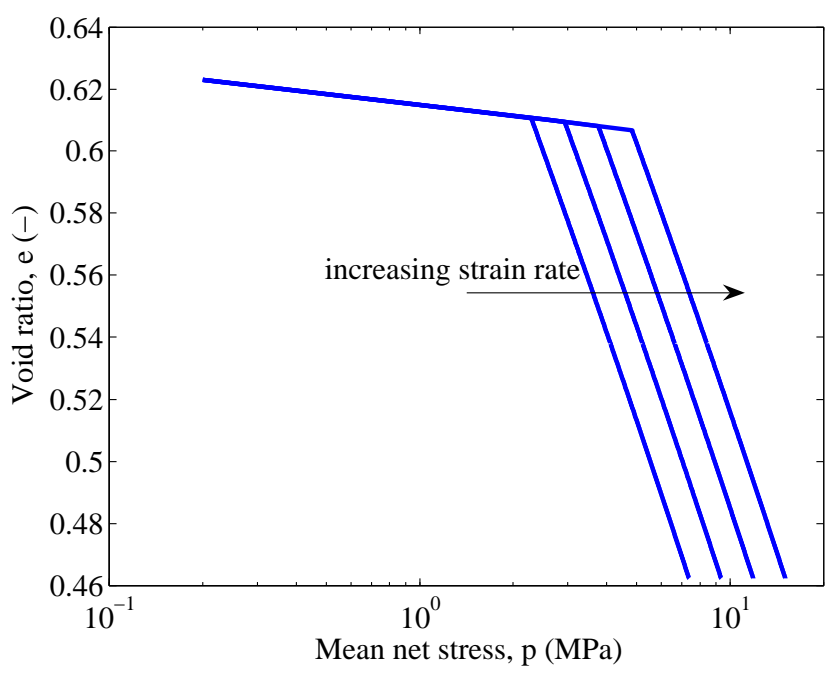

Figure 3: Simulation of constant strain-rate isotropic compression tests under various volumetric strain rates showing isotach behaviour (two following curves concern a volumetric strain rate increase by a factor 10).

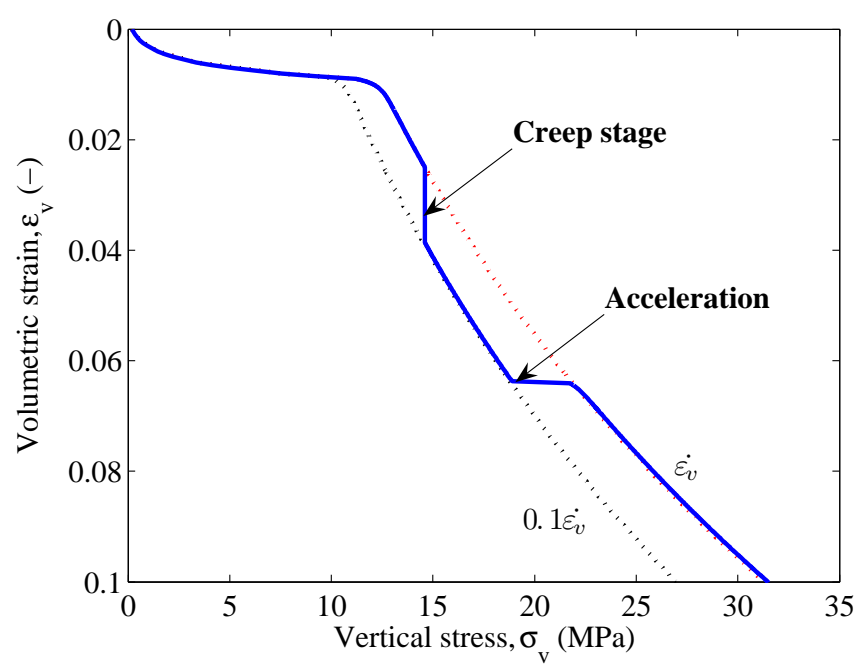

Figure 4: Simulations of constant rate of strain (CRS) oedometer tests at various strain rates (all simulations are performed at a constant suction of $2 \mathrm{MPa}$ ).

Table 1: Model parameters used in the simulations of Estreux and Lixhe chalks.

\begin{tabular}{llll}
\hline Parameter & Unit & Estreux & Lixhe \\
\hline$\kappa_{s}$ & - & $5 \cdot 10^{-4}$ & $5 \cdot 10^{-4}$ \\
$\kappa$ & - & 0.005 & 0.004 \\
$\lambda(0)$ & - & 0.12 & 0.15 \\
$r$ & - & 0.94 & 0.9 \\
$\beta$ & $\mathrm{MPa}^{-1}$ & 0.5 & 0.25 \\
$p_{c}$ & $\mathrm{MPa}$ & 0.002 & 0.01 \\
$k$ & - & 0.185 & 0.185 \\
$\dot{\varepsilon}_{v}^{r e f}$ & $\mathrm{~s}^{-1}$ & 0.5 & 0.5 \\
$p_{0}^{r e d}$ & $\mathrm{MPa}$ & 15.5 & 15.5 \\
$\alpha_{0}$ & - & 0.108 & 0.108 \\
$b$ & $\mathrm{MPa}^{-1}$ & 0.106 & 0.106 \\
\hline
\end{tabular}




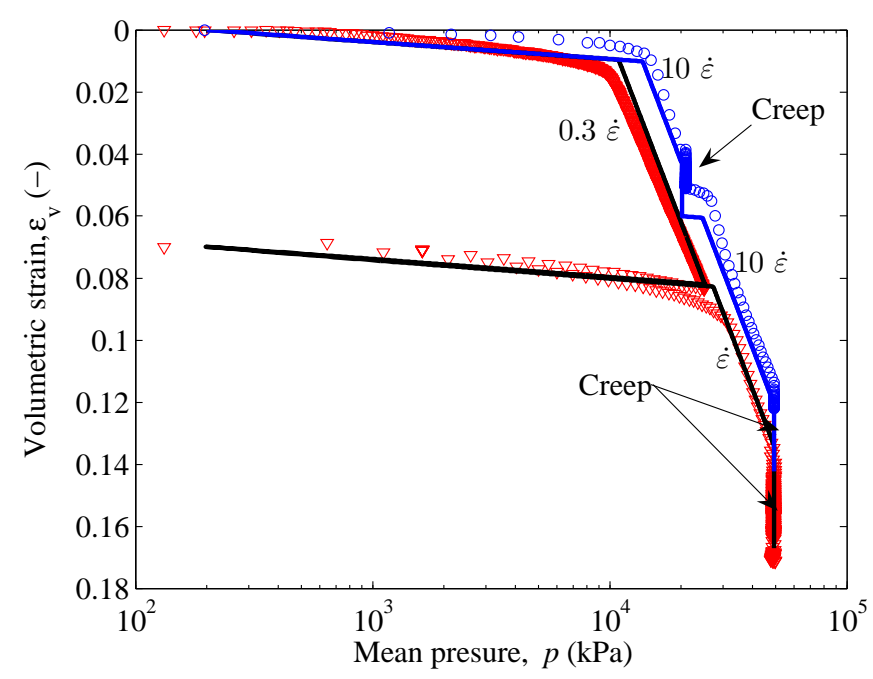

Figure 5: Isotropic compression at various rates, including creep stages: comparison between numerical simulations and experimental data on chalk from Lixhe under constant oil-water suction of $0.2 \mathrm{MPa}$.

\section{PERFORMANCE OF RASTRA}

Numerical simulations using RASTRA model are now presented in order to show the capabilities of the model in terms of coupled modelling of time and partial saturation effects. The model parameters used in the simulations presented in the following part of the paper are summarized in Table 1.

\subsection{Isotach framework}

Preliminary tests are performed to illustrate the capabilities of the model to reproduce the main features related to the isotach framework and which corresponds to RASTRA added value with respect to the original BBM. The parameters used in the "virtual" tests presented in Figures 3 and 4 correspond to those of Lixhe chalk in Table 1.

Figure 3 illustrates the isotach framework used in RASTRA model. It shows the simulation of constant strain-rate isotropic compression tests under various volumetric strain rates and a constant suction value for all tests (equal to $2 \mathrm{MPa}$ ). The change from one curve to the following corresponds to an increase by a factor 10 of the volumetric strain rate at which the compression is performed. It can be observed that an increase of the volumetric strain rate results as expected in the increase of the yield point. The figure also shows that the elastic and elastoplastic slopes of the soil response are not affected by the inclusion of time dependency into the constitutive model.

Figure 4 shows the effects of changes of the strain rate during an oedometric compression at constant rate of strain (CRS tests). The numerical test consists in three compression stages at two distinct strain rates (a fast strain rate corresponding to $10^{-6} \mathrm{~s}^{-1}$ and a slow strain rate, 10 times slower). After the first compression, a creep phase is simulated. The latter is nu- merically performed by simply decreasing the strain rate from the fast rate to the slow rate. It may be observed that the creep phase effectively induces irreversible strains at constant vertical stress and that the acceleration of the strain rate allows the material to undergo higher stresses (strain rate hardening) before plastic strains are generated again. Two simple compressions at fast and slow constant rates are also simulated for comparison purposes (dotted curves).

\subsection{Validation from experimental data}

A first comparison to experimental data is now proposed. Figure 5 presents experimental isotropic compressions on Lixhe chalk at various loading rates, including creep stages. It appears that RASTRA is able to reproduce not only qualitatively but also quantitatively the overall behaviour of reservoir chalk under partial saturation. Changes in strain rate and creep phases are satisfactorily reproduced. It may be noted that the experimental data seems to show a slight dependence of the elastic modulus upon strain rate (compare the initial slopes of the first parts of both compressions which are performed at two distinct applied strain rates). This observation is however not accounted for in RASTRA and the model response thus shows a unique response within the elastic domain (see also Figures 3 and 4).

Finally, an oedometer compression test on dry Estreux chalk (Nguyen et al. 2008) has been considered. The initial suction was estimated to $30 \mathrm{MPa}$. The standard multiple stage loading procedure was simulated imposing an equivalent loading rate derived from the known elapsed time of the test. During the test the mechanical loading was stopped at a total vertical stress of $20 \mathrm{MPa}$ and water was then injected within the sample under constant vertical stress. The material parameters corresponding to the elastoplastic part of RASTRA (that is those related to BBM) have been published by Nguyen et al. (2008) and have been considered for these simulations (Table 1). The missing viscous parameters for Estreux chalk have been assumed as a first estimate equal to the parameters obtained for Lixhe chalk. It should be noted that due to the particularly high value of suction at which the oedometer compression test is performed (30 MPa) a lower bound has been chosen for $\alpha$ (see Equation (6)) assuming $\alpha_{\min }=0.035$. The results of the simulations are presented in Figure 6. As it can be observed, the instantaneous compaction due to water injection at the end of the compression is clearly underestimated by the model if viscous behaviour is neglected (Figure $6(\mathrm{a}))$. In other words, the mechanism of suction hardening proposed by BBM via the LC curve, frequently used in unsaturated soil mechanics to simulate instantaneous compaction under decreasing suction (wetting) is not sufficient to predict such a large 




(a) Elastoplastic simulation (BBM).

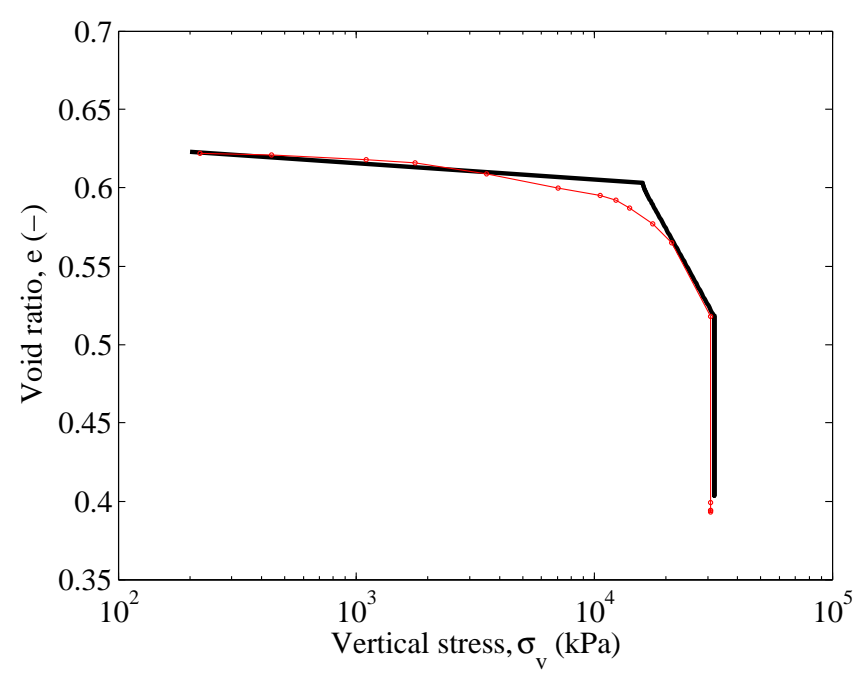

(b) Elasto-visco-plastic simulation (RASTRA).

Figure 6: Simulation of wetting induced compaction during one-dimensional compression test on Estreux chalk.

compaction. Actually, if one adds to the simulation a creep phase following water injection, RASTRA model predicts a total amount of collapse which compares well to the experimental data (see Figure 6(b)).

\section{CONCLUSIONS}

An elasto-visco-plastic model for partially saturated geomaterials has been presented. Based on the isotach framework, it extends the Barcelona Basic Model proposed by Alonso et al. (1990) for partially saturated materials to take into account time effects in terms of susceptibility to applied strain rate and creep phenomena. These time effects have been restricted to the plastic part of the model, assuming an inviscid elastic behaviour.
Numerical simulations have demonstrated the capabilities of the model to qualitatively and quantitatively address fundamental aspects of the rate dependent behaviour of partially saturated geomaterials. Foreseen improvements to RASTRA include a refined dependency upon suction of the parameter $\alpha$ of Equation (6). This refinement could also include the wettability of the saturating fluid to catch the behaviour illustrated in Figure 1.

\section{REFERENCES}

Alonso, E. E., A. Gens, and A. Josa (1990). A constitutive model for partially saturated soils. Géotechnique 40(3), 405-430.

Bjerrum, L. (1967). Engineering geology of norwegian normally-consolidated marine clays as related to settlement of buildings. Géotechnique 17, 81-118.

De Gennaro, V., J. M. Pereira, M. Gutierrez, and R. J. Hickman (2009). On the viscoplastic modelling of porous chalks. Italian Geotechnical Journal 1/2009, 44-64.

Leroueil, S. and M. E. S. Marques (1996, Nov.). Importance of strain rate and temperature effects in geotechnical engineering. In Measuring and modeling time dependent soil behaviour, Proc. of the ASCE Convention, Number 61, Washington, DC, USA, pp. 1-60. ASCE.

Nguyen, H. D., V. De Gennaro, P. Delage, and C. Sorgi (2008). Retention and compressibility properties of a partially saturated mine chalk. In D. G. Toll, C. Augarde, D. Gallipoli, and S. J. Wheeler (Eds.), Unsaturated Soils: Advances in Geo-Engineering, Durham, UK, pp. 283-289. Taylor \& Francis Group.

Oldecop, L. A. and E. E. Alonso (2007). Theoretical investigation of the time-dependent behaviour of rockfill. Géotechnique 57(3), 289-301.

Pasachalk (2004). Mechanical behaviour of partially and saturated chalks fluid-skeleton interaction: main factor of chalk oil reservoirs compaction and related subsidence - part 2, final report. Technical report, EC Contract no. ENK6-2000-00089.

Pereira, J. M. and V. De Gennaro (2009). Time dependent behaviour of fluids filled geomaterials: application to reservoir formations. In H. I. Ling, A. Smyth, and B. Raimondo (Eds.), Poromechanics IV - Proceedings of the 4th Biot Conference on Poromechanics, Columbia University, New-York, pp. 983988. DEStech Publications, Inc.

Pereira, J. M., H. Wong, P. Dubujet, and P. Dangla (2005). Adaptation of existing behaviour models to unsaturated states: Application to cjs model. International Journal for Numerical and Analytical Methods in Geomechanics 29(11), 1127-1155.

Priol, G., V. De Gennaro, P. Delage, and T. Servant (2007). Experimental investigation on the time 
dependent behaviour of a multiphase chalk. In T. Schanz (Ed.), Springer Proc. Physics 112, Experimental Unsaturated Soil Mechanics, pp. 161-167.

Sorensen, K., B. Baudet, and B. Simpson (2007). Influence of structure on the time-dependent behaviour of a stiff sedimentary clay. Géotechnique 57(1), $113-124$

Tatsuoka, F. (2009). Rate effects on elastic and inelastic stress-strain behaviours of geomaterials observed in experiments. In H. I. Ling, A. Smyth, and R. Betti (Eds.), Poromechanics IV - Proceedings of the 4th Biot Conference on Poromechanics, Columbia University, New-York, pp. 43-56. DEStech Publications, Inc.

Šuklje, L. (1957). The analysis of the consolidation process by the isotache method. In Proc. 4th Int. Conf. on Soil Mech. and Found. Engng., Volume 1, London, pp. 200-206. 